POLSKA AKADEMIA UMIEJĘTNOŚCI

TOM XIII

KULTURA SŁOWIAN. ROCZNIK KOMISJI KULTURY SŁOWIAN PAU

2017

DOI $10.4467 / 25439561$ KSR.17.002.7872

\title{
ВЛАдИМИР ПоЛЯк
}

Консультационная фирма «Эльвик»

Rechowot, Izrael

\section{МЕТОДОСОФСКИЙ ПОДХОД К ИССЛЕДОВАНИЮ ГЕОКУЛЬТУРНЫХ КОНФЛИКТОВ (УКРАИНА, ПРИБАЛТИКА, ИЗРАИЛЬ)}

\author{
METHODOSOPHYCAL APPROACH TO THE RESEARCH \\ OF GEOCULTURAL CONFLICTS \\ (UKRAINE, BALTIC STATES, ISRAEL)
}

\section{Streszczenie}

Współcześnie najbardziej perspektywiczne podejście w rozumieniu rozwoju cywilizacji związane jest nie z geopolityką i geoekonomią, a geokulturą. Geokultura jest spośród nich najważniejsza. Kultura towarzyszy rozwojowi duchowemu ludzkości. W różnych okresach historii rolę przywódczą odgrywały inne narody, wypełniając określoną misję w rozwoju kultury. Współczesne konflikty na tle kulturowym z udziałem Słowian w różnych regionach świata: w zderzeniu z kulturą islamu, kulturą Zachodu, konflikty wewnątrzkulturowe (Rosja Ukraina) rodzą się na gruncie kultury religijnej bądź wyznaniowej. Sprzyja im niezrozumienie istoty przyczyn tych konfliktów przez elity światowe, które mentalnie związane są z przestarzałymi geoekonomicznymi i geopolitycznymi przekonaniami.

\section{Summary}

This article designates the theoretical and practical foundations of the methodosophycal approach - a synthesis of methodology and anthroposophy. This is a complex of modern humanitarian technologies, including intuitive drama, organizational-activity game and contemplative dialogue. Special attention is given to the method the contemplative dialogue. Contemplative dialogue as a method of communication was developed in 2012. It is founded on a special technique of communication with the spiritual world, based on conscious men- 
tal work on situation analysis and problem solution. We describe the theoretical basis of the method, its organization and implementation procedure. The author describes the existing practice of the dialogue method in his work of the consultant, as well as the experience of other researchers around the world. Describes the application of methodosophycal approach to research and solutions geocultural conflicts involving the Slavic population. The paper summarizes the results of the work of an international group of researchers at the material conflicts in countries such as Ukraine, Estonia, Israel.

Słowa klucze: metodosofia, metodologia, dialog kontemplacyjny kultur Key words: methodosophy, methodology, contemplative dialogue of cultures

\section{Эпоха славянской культуры как следующий этап развития мировой цивилизации}

Наиболее авторитетные на сегодня подходы к развитию мировой цивилизации: геополитический, геоэкономический и геокультурный. Геокультурный является наиболее продвинутым из них. Однако на сегодня этих подходов недостаточно, что было в частности показано в работе автора «Израиль и Россия в 21 веке: геополитика- геоэкономика- геокультура». ${ }^{1}$ Ведь по большому счету культура есть история развития человеческого духа, где на разных этапах ведущим является тот или иной народ, выполняющий определенную миссию развития культуры. Эта картина мира базируется на духовно-научном подходе или антропософии, философском течении, разработанным в начале 20 века Р. Штайнером. Ее идея состоит в том, что космос, социум и сам человек являются проявлениями духовного мира. Познав духовные законы, можно перенести гармонию Космоса и в человеческий социум. И антропософия уже ввела многие выявленные духовные закономерности в практику образования, медицины, экономики и управления.

Каковы же те закономерности, которые определяют историческое развитие? Из духовного мира исходят творческие импульсы, которые несут высокие духовные существа, а человек и народы, воспринимающие эти импульсы, являются сотворцами исторических процессов. В русле христианской традиции эти Духи народов имеют ранг Архангелов, которые через Ангелов передают свои импульсы отдельным личностям. В определенный период времени дух того или иного народа (и соответственно тот или иной народ) играет ведущую роль в развитии той или иной эпохи. Каждая эпоха имеет свой Дух времени, представленный Архаем. Это движение не прямолинейно, кроме правомерных духов в истории

${ }^{1}$ В. Поляк. Израиль и Россия в 21 веке: геополитика-геоэкономика- геокультура. Тель-Авив 2004, c. 200. 
действуют и так называемые отставшие духи, которые имеют свои собственные цели. В обыденном сознании их называют духами зла. В каждой эпохе человек развивает в себе те или иные душевные качества, которые наилучшим образом представлены в том или ином народе. Первой - была древнеиндийская, затем древнеперсидская, за которой последовала египетская культура. Четвертая - эпоха греко-латинской культуры. Человеку современной, пятой культурной эпохи, которая началась с 15 в. следует развивать душу сознательную, в которой крепнет силаиндивидуального Я. В начале эпохи ведущими являются англосаксонские народы, а во второй половине их должны сменить народы Центральной Европы. Для нас наиболее важным является положение, что нынешняя пятая послеатлантическая европейская эпоха передает свою эстафету шестой, где ведущую роль будут играть славянские народы, которые Штайнер называл народом Христа ${ }^{2}$.

Штайнер указывал на три ключевые черты славянских народов, которые являются провозвестниками шестой эпохи. Это - спиритуальность, сострадание (эмпатия) и стремление к свободе. Антропософия говорит, что конфликты между народами имеют духовную подоплеку. И в этом контексте понятно, что ряд мировых центров власти, инспирированных определенными духовными силами, не заинтересованы в том, чтобы переход к эпохе славянской культуры состоялся. Это и объясняет интенсификацию конфликтов с участием представителей славянской культуры.

\section{Методософский подход - комплекс современных гуманитарных технологий}

Другое оригинальное философское течение возникло в России в 50-х годах 20 века - методология Г.П. Щедровицкого ${ }^{3}$. Она полагает, что мир есть система мышления и деятельности людей. И в рамках ее был разработан уникальный метод исследования - организационно-деятельностные игры. Группа русскоязычных исследователей из разных стран, владеющих обеими парадигмами, начиная с 2000-х годов осуществляет синтез антропософии и методологии, в виде - методософии ${ }^{4}$. Она объединяет интеллектуальную традицию системомыследеятельного подхода с антропософией, представляющей картину духовного мира и практический опыт, основанный на этой онтологической картине. Методософия рассматривает ситуации и проблемы как «поле» взаимодействия разных факторов, не только материальных, но также эмоциональных как, например, страх или обида, и духовных: дух народа или дух времени.

2 Р. Штайнер,.Как достигнуть познания выстих миров. Москва 2002.

${ }^{3}$ Г. Щедровицкий, Мышление, понимание, рефлексия. Москва 2005. с. 770-783.

${ }^{4}$ А. Тыугу, Дети индиго. Новое поколение? Санкт Петербург 2009. 
Для этого применяются оригинальные технологии организации коммуникации: логика чувств, игровой канон, интуитивная драма и созерцательный диалог. В 2000 г. был разработан «Игровой Канон» ${ }^{5}$, который приводит к изменениям в душах и сознании людей, участвующих в игре, таким образом, что эти изменения впоследствии оказывают влияние на ситуацию в материальном мире. Интуитивная драма имеет определенные исторические корни в библиодраме и психодраме. В ней целостную и объективную картину ситуации визуализируют в пространстве с помощью группы людей, в отличие от организационно-деятелностных игр, где различные факторы представлены в виде графических схем ${ }^{6}$.

\section{Метод созерцательного диалога с использованием схемы мыследеятельности}

Схема мыследеятельности подразумевает наличие трех поясов: мыследействия, мыслекоммуникации, чистого мышления и три основные позиции. Первый коммуникант, человек, столкнувшийся с проблемой в поясе мыследействия. Для ее решения он вступает в коммуникацию с другим позиционером и выходит в пояс мыслекоммуникации. Коммуникация с методологом помогает выйти в пояс чистого мышления и найти решение проблемы. К сфере чистого мышления относятся идеи, схемы и т. д.

В методософском подходе за чистым мышлением стоит сфера духовного мира. Здесь действуют сущностные силы, которые Платон определял как те, что порождают сами эйдосы. Иными словами, это определенные духовные существа. Именно они стоят за тем, что на внешнем материальном плане выступают как те или иные ситуации, мысли, эмоции или поступки. Метод диалога позволяет созерцать истинное существо проблемы и, вступив с ним в диалог - найти решение. Своеобразная «дорожная карта» духовного мира, типология, классификация и иерархия духовных существ дается в антропософии с учетом терминологии различных духовных традиций: христианства, иудаизма а также восточных и гностических учений.

В созерцательном диалоге выделяются те же три позиции, которые называются: медитант - «зеркало»-методик. В ходе коммуникации происходит следующее: медитант формулирует проблему. «Зеркало» отражает позицию медитанта (его обыденное нерефлектирующее я). Медитант выходит в рефлексивную позицию, умозрительно занимая позицию существа, стоящего за тем или иным

${ }^{5}$ И. Фишман, Сумма методов, «Методология в России» 2008.

${ }^{6}$ И. Аристова, Интуитивная или образная драма, «Методология в России» 2007. 
переживанием. Посредством вопросов фасилитатор переводит процесс в пояс чистого мышления и, обладая типологией духовного мира, задает вопросы для классификации рода существ.

В этот момент начинается «переход» в духовный мир. В случае правильной фиксации имени существа происходит следующее. Медитант удерживает одновременно позицию существа и вновь артикулирует Я -позицию. Речь идет о том, что приняв теперь ясный сигнал о том, какого рода существо стоит за его проблемой медитант может расшифровать сообщение и определить свою задачу. Таким образом, возникает связь между поясами чистого мышления и духовного мира. Сознание выходит на новый уровень, хорошо известный из работ по трансперсональной психологии. Оно переживается как состояние креативности. Далее формулируется задача, реализацию которой возможно перевести в практический план. Как правило, данная задача довольно далека от того проблемного «облака», в котором она впервые явилась человеку?. За период 2003-2015 гг. исследовательская группа, в которой состоит автор данной работы, провела множество крупных семинаров по межнациональным конфликтам с использованием данных методов в Израиле, Германии, Эстонии, Литве, Украине, Армении и США.

\section{Эстония}

В 2007 г. в Эстонии резко обострились отношения между русскоязычной общиной, составляющей примерно треть всего населения страны и эстонскими властями, связанные с переносом памятника Советскому солдату. Протесты были очень жестко подавлены полицией. Было множество пострадавших. Для исследования и гармонизации ситуации нами была проведена интуитивная драма с участием обеих сторон. Среди ключевых фигур были выбраны факторы, видимые на физическом плане: Посредник, Эстонец, Представитель русскоязычной общины Эстонии, так и нематериальные: Свобода, Страх, Любовь, Дух эстонского народа, Дух русского народа и Дух времени. Анализ показал подлинную, духовную причину конфликта: непонимание исторического смысла пребывания русских на территории Эстонии. Он состоит в том, что у русскоязычной общины есть своя миссия, через интеграцию культур - передать эстонскому народу определенные качества, присущие русской культуре. У эстонцев силен страх смерти, исчезновения, тогда как у русских сильна традиция воскресения.

${ }^{7}$ Более подробно об этом методе В. Поляк, Методы коммуникации с Логосом. Санкт Петербург 2015. Материаль Международной научной конференции «Наука о коммуникации как дисциплина и область знания в современном мире: диалог подходов», Высшая школа экономики в Москве, http://commconferencehse.ru/, дост. 12.10.2017. 
Сосуществование двух народов необходимо для того, чтоб русские могли передать эстонцам определенные душевные качества, необходимые для их развития. Поэтому на духовном плане между духами народов было заключено некое соглашение. Были сделаны также практические выводы, что для гармонизации ситуации необходимо дать возможность русскоязычной молодежи вернуться к своим корням, а эстонцам - восстановить связь со своими духовными ценностями.

\section{Израиль}

С 2004 г. мы ведем работу по теме арабо-израильского конфликта, а также миссии русскоязычной общины в Израиле и ее роли в этом конфликте. В этих работах исследовалось влияние таких факторов, как «судьба еврейского народа», «судьба арабского народа», «страх», «прощение», «вечный ресурс, связанный с Иерусалимом», «дух Русского народа».

Главный вывод был таков: необходимо изучать духовную сторону процессов, происходящих как в Израиле, так и в арабских странах. Следует выяснить, какова на нынешнем этапе миссия государства Израиль. Если ему не дают стать таким же государством, как все остальные, следовательно, должен быть какой-то высший смысл в его существовании. Возможно, он в том, чтобы вернуть социальным законам их духовное содержание, создать социум, пронизанный духовностью. Точно также является проблемой и формирование миссии арабского мира на современном этапе. В свое время она была заменена в исламе идеей завоевания мира неверных, которая на сегодня трансформировалась в идею глобального джихада и других глобальных идей современный ислам пока не выдвинул.

Также особую роль в этих процессах играет, наличие большой русскоязычной общины, составляющей до четверти населения всего Израиля. Причем среди них примерно до трети составляют этнические русские, облученные духом русской культуры, связанной с христианством. И здесь идет параллельно два процесса: процесс интеграции русскоязычной общины в израильское общества (что сопровождается на деле серьезной конфронтацией) и процесс участия русскоязычной общины в арабо-израильском конфликте. В работе с участием представителей русскоязычной общины в октябре 2009 г. были найдены первые четыре конкретных шага в работе миротворца. Первый - обретение мира в самом себе, второй - умение транслировать идею мира - в социум, третий способность построить сообщество миротворцев, четвертый - принять в душу силы любви, выраженные в образе Христа.

В ходе работ над процессом духовной интеграции русскоязычной общины стало ясно, что нельзя дать русскоязычной молодежи оторваться от своих корней. Необходимо понять, что обусловило необходимость взаимодействия Духов 
еврейского и русского народов. Для этого необходимо исследовать архетипы русского и еврейского народов, чтобы увидеть их миссии на сегодняшнем этапе развития в соответствии с Духом времени. В целом миссия русской общины в Израиле состоит в участии в построении современного общества, отличающегося подлинной духовностью. Однако, определенные глобальные силы стремятся к контролю над духовными ресурсами региона, и чтобы замаскировать эту цель, инициируется конфликт с палестинскими арабами. В этом и есть причина непрекращающегося конфликта в регионе - стремление мировых сил к контролю над духовными ресурсами региона с помощью давления на Израиль.

Таким образом, одним из главных источников непрерывных конфликтов вокруг Израиля является вопрос о духовном ресурсе, являющемся источником развития человеческих качеств. Вечный ресурс Иерусалима можно трактовать как импульс души сознательной. Это означает, что сегодня люди стоят перед задачей одухотворить интеллект.

В ходе дальнейших семинаров были найдены упражнения направленные на обретение внутреннего мира и на то, как учиться одухотворять интеллект. Но это касается развития индивидуальности. Если же говорить о полном развитии души сознательной, то надо говорить о социальном импульсе. Как ответ на «социальные требования нашего времени» стоит необходимость развития социальной трехсферности ${ }^{8}$.

\section{Украина}

В 2013-2015 гг. было проведено несколько интуитивных драм и диалогов по ситуации на Украине. Последняя работа была проведена в начале декабря 2015 г. во время рождественского поста.

Вопрос звучал так: как сегодня воспринимается ситуация на Украине в контексте темы: Славяне и геокультура. В ходе диалога возникло переживание похожее на ожидание некоей беременной женщины - Женщина в Надежде (по украински). И ее задача звучала так: она должна быть цельной, внимательной, аккуратной, чтобы Рождение произошло правильно, потому что через это должен родиться некий новый импульс. Она должна прислушиваться к тому, что рождается. Это был последний диалог, но перед этим были и другие работы, в том числе интуитивные драмы, в которых, всплывали как ключевые образы Софии Оранты и казака- характерника. София Оранта - образ молящейся Богоматери, известный с древнейших времен. Представляют ее в жесте заступнической

8 Это социальная теория, разработанная Р. Штайнером, которая описывает социум как совокупность трех сфер (духовной, правовой и экономической), каждая из которых имеет собственные закономерности. 
молитвы. Один из наиболее известных изображений на сегодня - в Софийском соборе Киева. Казак - характерник - казак, наделенный магическими способностями, отчасти его образ описан в повестях Н. Гоголя.

Я приведу вкратце те выводы, к которым мы пришли, обобщая предыдущие работы и вышеуказанный диалог. В настоящий момент усилиями многих сил, создан извращенной образ Украины, в определенном смысле геополитического двойника. Этот образ доминирует как в экспертном, так и в обыденном сознании. Это представление о том, что Украина фактически состоит из двух частей: западной и восточной. Как будто у Украины нет своей траектории. Однако это не так. У Украины есть свой путь и своя миссия. Ее пытаются предать забвению. Для этого в свое время было предпринято уничтожение этой срединной части, включающей территорию от Чернигова до Черкасс. В том числе посредством Голодомора. Это было уничтожение духовного стержня, который тянется от Одессы к Киеву. Этот непробужденный центр является тем, за что идет борьба, чтоб он не проснулся, либо он будет поглощен западом - неправомерным будущим, который хочет пройти через славянскую эпоху и пойти вперед, либо востоком, который хочет повернуть его назад. Поэтому эта борьба между прошлым и будущим. Это и есть борьба, чтобы не появилась настоящая, подлинная славянская культура.

\section{Интерпретация последнего диалога}

Образ Девы, ожидающей младенца имеет несколько граней. Одна грань это тот круг людей, которые сознательно несут импульс будущей шестой культуры и взяли на себя эту миссию, в частности представители методософского движения. Вторая грань - место Украины в этой мистерии. Славянские земли это планетарная утроба, в которой этот младенец вызревает. Это определенным образом связано с Мистерией рождества. Основная мистерия, которая должна состоятся - это рождение высшего я. Это собственно рождение Я, связанного с Христом. Казак - характерник и София Оранта - два аспекта этого высшего я - связь с высшими иерархиями и познавательная работа. Будущая культура может возникнуть только тогда, когда в сознании людей может возникнуть сумма прообразов, соответствующая шестой культуре. Но просто созерцанием здесь не обойтись. И здесь возникает образ казака-характерника, который идет на помощь. Он с помощью суммы методов, реализуемых в социальной жизни, с помощью методософии помогает рождению высшего я. Вместе это и дает апокалиптический образ девы, находящейся в мистерии ожидания, в ожидании рождения нового импульса, импульса шестой славянской культуры.

Нынешние конфликты с участием представителей славянской культуры в разных регионах: в столкновениях с исламской культурой (Израиль), западной 
культурой - Прибалтика, межкультурные конфликты Россия - Украина имеют в своей истинной основе - духовные причины. А именно, определенные мировые силы с помощью влияния неправомерных духовных сил пытаются помешать развитию славянского мира как зародыша будущей славянской культуры, обладающей общегуманистическими чертами. Этому способствует непонимание подлинных причин ситуации нынешними мировыми элитами, которые зачастую находятся в плену устаревших геополитических, геоэкономических и неправильно понятых геокультурных стереотипов. Для адекватного анализа ситуации необходимо видение духовных причин конфликтов, исследования в области духов народа и Духа времени, подготовки истинных посредников в межнациональных конфликтах. В качестве дальнейших шагов по развитию этих исследований необходим диалог между всеми силами, между представителями всех цивилизаций и, особенно, между представителями славянской культуры. То, что может нас по настоящему объединить и помочь это подлинный диалог с духовным миром. И особенно важно, что в таком диалоге могут принять участие представители тех духовных центров, которые связаны с зарождением и развитием христианства: Иерусалим - Киев - Москва. А Краков может явиться тем самым истинным посредником, о котором шла речь выше, в разрешении геокультурных конфликтов.

\section{Библиография}

Аристова, К., Интуитивная или образная драма. «Методология в России». http://bdn-steiner.ru/modules.php?name=Books\&go=page\&pid=5601.

Бондарев, Г., События на Украине и возможный сиенарий будущего. Methodosophia. Методология духовной науки Рудольфа Штайнера, антропософии. http://anthroposophie-methodologie.org/wp-ontent/uploads/2015/07/\%D0\%91\%D1\%80.1.pdf.

Поляк, В., Методософский подход как ответ на вызовы времени на примере арабоизраильского конфликта [b:] Всемирный форум духовной культуры, ред. А. Шилина и др. Астана 2011.

Поляк, В., Методы коммуникаиии с Логосом. Санкт Петербург 2014.

Фишман, И., Сумма методов. «Методология в России». http://circleplus.ru/content/summa/22/summa metodov chistovik.pdf.

Тыугу, А., (2009). Дети индиго. Новое поколение?, Санкт Петербург 2009.

Штайнер, Р., Как достигнуть познания высших миров. Москва 2002. 